\title{
Regulation of Hepatic Stem/Progenitor Phenotype by Microenvironment Stiffness in Hydrogel Models of the Human Liver Stem Cell Niche
}

\author{
Oswaldo A. Lozoya ${ }^{1,2}$, Eliane Wauthier ${ }^{1,2}$, Rachael Turner ${ }^{1,2}$, Claire Barbier $^{1,2, \dagger}$, Glenn D. \\ Prestwich $^{3}$, Farshid Guilak ${ }^{4}$, Richard Superfine ${ }^{5}$, Sharon R. Lubkin ${ }^{1,6}$, and Lola M. Reid ${ }^{1,2, *}$ \\ ${ }^{1}$ Joint Department of Biomedical Engineering, North Carolina State University, Raleigh, NC and \\ UNC School of Medicine, Chapel Hill, NC \\ 2Department of Cell and Molecular Physiology and Program in Molecular Biology and \\ Biotechnology, Lineberger Comprehensive Cancer Center and Center for Gastrointestinal and \\ Biliary Disease Biology, UNC School of Medicine, Chapel Hill, NC \\ ${ }^{3}$ Department of Medicinal Chemistry and Center for Therapeutic Biomaterials, University of Utah, \\ Salt Lake City, UT \\ ${ }^{4}$ Departments of Surgery, Biomedical Engineering, Mechanical Engineering and Materials \\ Science, Duke University Medical Center and Pratt School of Engineering, Durham, NC \\ ${ }^{5}$ Department of Physics and Astronomy, UNC College of Arts and Sciences, Chapel Hill, NC \\ ${ }^{6}$ Department of Mathematics, North Carolina State University, Raleigh, NC
}

\begin{abstract}
Human livers have maturational lineages of cells within liver acini, beginning periportally in stem cell niches, the canals of Hering, and ending in polyploid hepatocytes pericentrally and cholangiocytes in bile ducts. Hepatic stem cells (hHpSCs) in vivo are partnered with mesenchymal precursors to endothelia (angioblasts) and stellate cells, and reside in regulated microenvironments, stem cell niches, containing hyaluronans (HA). The in vivo hHpSC niche is modeled in vitro by growing hHpSC in two-dimensional (2D) cultures on plastic. We investigated effects of 3D microenvironment, mimicking the liver's stem cell niche, on these hHpSCs by embedding them in HA-based hydrogels prepared with Kubota's Medium (KM), a serum-free
\end{abstract}

(c) 2011 Elsevier Ltd. All rights reserved.

*Corresponding Author: LM Reid, UNC School of Medicine, Campus Box \# 7038, Glaxo Building Rms. 32-36, Chapel Hill, NC 27599. Phone: 919-966-0347; FAX: 919-966-6112. Lola.M.Reid@gmail.com .

$\dagger^{\dagger}$ Posthumous

Author contributions: The original ideas for the project were by LM Reid and OA Lozoya. OA Lozoya performed all mechanical characterization of hyaluronan hydrogels under the supervision of F Guilak in the Orthopaedic Bioengineering Laboratory at Duke University (diffusivity) and R Superfine in the Center for Computer Integrated Systems for Microscopy and Manipulation at UNC Chapel Hill (rheometry). LM Reid supervised all aspects of human cells, matrix chemistry and biology, and biological assays. E Wauthier and R Turner did preparations to isolate hepatic stem cells and hepatoblasts. E Wauthier and C Barbier assisted with miscellaneous aspects of the project as needed. $\mathrm{R}$ Turner provided background information from earlier studies with hepatic stem cell cultures in hydrogels. GD Prestwich supplied hyaluronan materials for the experiment. OA Lozoya performed all experiments, assays, microscopy, data analysis, created all Figures and Tables, and wrote initial drafts of the manuscript. C Barbier and SR Lubkin helped edit the initial drafts. SR Lubkin advised on statistical methods for data analysis. OA Lozoya and LM Reid performed final edits leading to manuscript submission. The authors declare that they have no conflicts.

Publisher's Disclaimer: This is a PDF file of an unedited manuscript that has been accepted for publication. As a service to our customers we are providing this early version of the manuscript. The manuscript will undergo copyediting, typesetting, and review of the resulting proof before it is published in its final citable form. Please note that during the production process errors may be discovered which could affect the content, and all legal disclaimers that apply to the journal pertain. 
medium tailored for endodermal stem/progenitors. The KM-HA hydrogels mimicked the niches, matched diffusivity of culture medium, exhibited shear thinning and perfect elasticity under mechanical loading, and had predictable stiffness depending on their chemistry. KM-HA hydrogels, which supported cell attachment, survival and expansion of hHpSC colonies, induced transition of hHpSC colonies towards stable heterogeneous populations of hepatic progenitors depending on KM-HA hydrogel stiffness, as shown by both their gene and protein expression profile. These acquired phenotypes did not show morphological evidence of fibrotic responses. In conclusion, this study shows that the mechanical properties of the microenvironment can regulate differentiation in endodermal stem cell populations.

\section{Keywords}

maturational lineages; human hepatic stem cells; human hepatoblasts; hyaluronans; microenvironment mechanical properties; differentiation

\section{INTRODUCTION}

The liver is one of the most complex organs in the body and is responsible for toxin removal, production of bile and hormones, regulation of nutrients, and synthesis of serum proteins [1]. Liver is organized in acini with a hexagonal shape and six sets of portal triads at the vertices, each containing a single hepatic artery, portal vein and bile duct. A central vein connected to the vena cava occupies the center of each acinus. Plates of liver cells, the maturational lineages of the epithelia and their partner mesenchymal cells, extend from the portal triads to the central vein. By convention, liver acini are divided into zones: zone 1 is periportal; zone 2 is midacinar; and zone 3 is pericentral [2].

Changes in matrix chemistry parallel the progression of cell maturity across liver zones and stabilize interactions of signals (matrix and soluble ones) with liver cells. The stem cell niches, the canals of Hering in zone 1, host three stem/progenitor populations: hepatic stem cells (hHpSCs), angioblasts and hepatic stellate cell precursors. These stem/progenitor populations reside in a microenvironment of soluble paracrine signals and an extracellular matrix of hyaluronans (HAs), an integrin $\alpha_{6} \beta_{4}$-binding laminin form (presumably laminin-5), collagen III, forms of minimally sulfated chondroitin sulfate proteoglycans (CSPGs) and no collagen type I or IV or heparan sulfate proteolgycans (HS-PGs) [3, 4]. As cells transition from the stem cell niche into the hepatoblasts (hHBs) partnered with endothelial and hepatic stellate cell precursors, the microenvironment shifts to distinct soluble signals in association with collagen types III and IV, $\alpha_{\mathrm{V}} \beta_{1}$ integrin-binding laminins, more highly sulfated forms of CS-PGs and minimally sulfated forms of HS-PGS. Each successive lineage stage involves phenotypic changes in the cells and chemical changes in the paracrine signals [5-8]. The matrix components, particularly the PGs, form complexes with growth factors and cytokines that signal liver cells in a stable fashion, dictating stepwise differentiation to adult fates across the hepatic maturational gradient [9].

Although liver can regenerate within weeks after acute injury [10], organ transplantation is the only established treatment for patients with liver failure. Therapeutic strategies under development include transplantation of liver cells in patients through grafting and bioartificial livers as assist devices [11]. We pursue these technologies by using purified human hepatic stem cells (hHpSCs) and their partner mesenchymal cells, angioblasts and hepatic stellate cell precursors, incorporated within biomaterials mimicking the stem cell niche $[11,12]$. We have shown that cell grafting helps transplanted cells remain within target tissues, facilitates expansion and vascularization, and differentiates cells to desired adult fates [11]. 
In the past, we have analyzed the effects of matrix and soluble signals on hepatic progenitors. We have completed multiple studies of these cells under ex vivo conditions and in which we analyzed the biochemical effects of the niche paracrine signals [4, 9, 13-17]. Still, the effects of mechanical properties of the microenvironment on hHpSCs, hepatoblasts (hHBs) and committed progenitors and their associated mesenchymal cells are unknown. Understanding the role of microenvironment mechanics on hepatic stem/progenitor cell is extremely important to liver tissue engineering for two reasons: first, it tests whether placement of these cells ex vivo or in vivo through grafting can induce maturation of liver tissue without fibrotic responses; and second, it determines if mechanical induction within defined microenvironments with controllable properties is a useful approach to regulate maturation of hepatic progenitors. Here, we studied the effects of mechanical properties of the 3D microenvironment on embedded hHpSCs colonies. We obtain hHpSC colonies, our experimental model of the human liver's stem cell niche that includes hHpSCs and a small fraction of mesenchymal partners, by culturing parenchymal fractions of digested fetal liver on plastic with Kubota's Medium (KM), a serum-free hormonally defined medium tailored for endodermal progenitors [4, 14, 18-20]. Our work defines a method to assess mechanical effects on stem cell populations within a defined 3D microenvironment that is experimentally predictable and repeatable, which can also be extended to other determined stem cell populations.

\section{MATERIALS AND METHODS}

This section is an abbreviated version of the experimental methods. For further details, see Supplementary Methods (online).

\section{Kubota's Medium (KM)}

Detailed methods for preparing KM, a tailored serum-free medium that expands stem cells and progenitors but not mature cells $[4,14,18,19]$, are available elsewhere [20].

\section{Hyaluronans (HA) and their cross-linker, PEGDA}

Thiol-modified HA derivatives, obtained from a commercial source under the name of HyStem Hyaluronan Hydrogels (Glycosan Biosciences, Salt Lake City, UT), include two dry reagents: CMHA-S (Glycosil) and PEGDA as cross-linker. Specific concentrations of CMHA-S and PEGDA were mixed in balanced KM (pH 7.4) into different KM-HA formulations, as summarized in Table 1.

\section{KM-HA rheometry}

Cloning cylinders (Cole-Parmer, Vernon Hills, IL) were used as casts for uncured, freshly mixed liquid KM-HAs (500- $\mu$ l samples, 4 samples per KM-HA formulation). Rheological properties of cell-free KM-HAs were tested with an AR-G2 cone-and-plate (CAP) rheometer (TA Instruments, New Castle, DE) under oscillatory frequency sweeps (shear stress amplitude: $0.6 \mathrm{~Pa}, 0.01 \mathrm{~Hz}-100 \mathrm{~Hz}$ frequency range). Testing data was processed with post-processing software and regression to rheological constitutive models [21].

\section{Diffusivity assays}

Uncured, freshly mixed liquid KM-HAs were casted into individual wells of a 24-well plate (200- $\mu$ l volume per formulation, sample thickness: $~ 1 \mathrm{~mm}$ ), followed by overnight incubation using KM supplied with fluorescein-conjugated 70-kDa Dextran (D70, Invitrogen, Carlsbad, CA) before testing. Diffusion coefficients of KM-HA hydrogels, measured by fluorescence recovery after photobleaching (FRAP) with a laser scanning 
confocal microscope (Zeiss LSM 510; 5 photobleaching spots, $400 \mu \mathrm{m}$ into KM-HA), were calculated with post-processing curve-fitting analysis routines are described elsewhere [22].

\section{Culture selection for hHpSCs and seeding of KM-HA hydrogels}

Human fetal liver obtained from an accredited agency (Advanced Bioscience Resources, Alameda, CA) was freshly processed and cultured with KM on plastic for 3 weeks, which resulted in culture selection for colonies of hHpSCs (2,000 - 5,000 cells/colony). These colonies of hHpSCs were isolated by pipette aspiration and then mixed into KM-HAs by pipetting (Table 1). Samples of hHpSC-seeded KM-HAs (0.15-ml volume, seeding density: $80 \mathrm{hHpSC}$ colonies/ml) were delivered, as freshly mixed liquid KM-HAs, into 10-mm diameter tissue inserts (Nunc, Rochester, NY; sample thickness: $\sim 2 \mathrm{~mm}$ ). KM was replaced daily for 1 week.

\section{Viability assays}

Viability of hHpSC colonies in KM-HAs (4 samples per KM-HA lettered formulation, 0.15$\mathrm{ml}$ samples) was determined by reduction assays of alamarBlue ${ }^{\circledR}$ reagent (AbD Serotec, Kidlington, UK) every other day starting on day 2 post-seeding after 24-hour incubation period.

\section{Quantitative Real Time PCR (qRT-PCR) analyses}

Total RNA was extracted from positive control cell lines, hHpSC colonies grown on plastic, freshly isolated hHBs, and hHpSCs embedded in KM-HA. Gene-specific primers (Supplementary Table 1) were validated using positive control cell lines. Gene expression baselines for hHBs and hHpSCs colonies were determined using data from 3 different fetal livers. Gene expression of KM-HA-embedded hHpSCs in 6 different KM-HA formulations (4 samples each, 0.15-ml samples) was measured with hHpSC colonies obtained from the same fetal liver, incubated in parallel with daily KM changes, and collected after 1 week of culture. We fully repeated this procedure for 2 different fetal human livers. Quantitative Real Time PCR (qRT-PCR) was performed with an Applied Biosystems ${ }^{\circledR} 7500$ Real-Time PCR System. All measurements were normalized to GAPDH by absolute quantification methods described elsewhere [23, 24].

\section{Analyses of secreted factors}

Culture medium of hHpSC-seeded KM-HAs was collected daily for 1 week. Hepatic function of KM-HA-embedded hHpSCs was measured by enzyme-linked immunosorbent assays (ELISA) for secreted AFP (ALPCO Diagnostics, Salem, NH), albumin (Bethyl Laboratories, Montgomery, TX) and urea (Bio-Quant Diagnostics, San Diego, CA).

\section{Histology and sectioning}

Samples of hHpSC-seeded KM-HAs were fixed with $4 \%$ buffered paraformaldehyde after 1 week of culture, prepared as $15 \mu \mathrm{m}-20 \mu \mathrm{m}$ thick cryosections, and stored frozen at $-80^{\circ} \mathrm{C}$ until staining. Thinner sections were not feasible due to KM-HA hydrogel handling properties.

\section{Immunohistochemistry}

Cryosections of hHpSC-seeded KM-HAs were washed at room temeperature with PBS, blocked with goat serum, and incubated with primary antibodies to various hHpSC differentiation markers, followed by fluorophore-conjugated secondary antibody incubation (fluorescence mounting media supplemented with DAPI). Relevant cell lines were used as positive controls for primary antibody validation (Supplementary Table 2). 


\section{Fluorescence and laser confocal microscopy}

Fluorescently labeled sections of KM-HA-embedded hHpSCs were imaged by fluorescence and laser confocal microscopy. Negative isotype controls were used to normalize backgrounds. Imaging performed with an Olympus IX70 Inverted Fluorescence Microscope or Leica SP2 Laser Scanning Confocal Microscope.

\section{Statistical analysis}

Mechanical characterization data reported within 95\% confidence intervals per engineering conventions. Molecular biology experiments reported as mean \pm standard error of the mean in charts or within $99 \%$ confidence intervals for side-to-side comparison (as indicated).

Significance of gene expression levels with respect to hHpSCs and hHBs (p-value: $*<0.05$, $* *<0.01, * * *<0.001)$ was determined by two-tailed Student's t-test. Significance across KM-HAs also reported by both two-tailed Student's t-test and two-tailed F-test (Supplementary Fig. 1). All measurements were performed at least in duplicate. Principal Component Analysis (PCA) of gene expression profile was performed using relative mRNA expression data from $\mathrm{hHpSCs}$ and hHBs for all markers in logarithmic scale. Significance of gene expression profile with respect to PC scores was evaluated for hHpSCs, hHBs and across KM-HAs (two-tailed Student's t-test; p-value: $*<0.05, * *<0.01, * * *<0.001$ ).

\section{RESULTS}

\section{Mechanical properties of cell-free HA hydrogels}

All HA-based hydrogels were mixed from equivalent components in different proportions (Table 1) using Kubota's medium (KM), a serum-free, hormonally defined medium tailored to select for endodermal stem cells and progenitors in culture $[4,14,18,19]$. From this point forward, these hydrogels are referred to as KM-HAs to distinguish them from those described elsewhere [25].

Stiffness, viscoelasticity and viscosity of KM-HAs depended on their chemistry (Table 1). KM-HAs maintained a constant stiffness across broad forcing frequency ranges while exhibiting perfect elasticity (Fig. 1a); they also exhibited shear thinning (Fig. 1b). The concentrations of CMHA-S and PEGDA determined the mechanical properties of KM-HAs (Fig. 2a). Also, diffusion differences between KM-HAs and KM were negligible and statistically insignificant, with coefficients ranging between 8 and $10 \mu \mathrm{m}^{2} / \mathrm{s}$ (Fig. 2b).

\section{Stiffness of KM-HAs regulates the maturational lineage stages of hHpSCs}

Size, morphology, viability and proliferation of hHpSCs in KM-HAs-2D-grown colonies of hHpSCs have a roughly round shape and are well delimited at their edges when cultured on plastic $[14,20]$. When seeded within KM-HAs, hHpSCs abandoned their 2D flat configurations and agglomerated into spheroids or folded into complex 3D structures (Fig. 3a). After 1 week of culture, cell morphology became diverse with some cells enlarging to about $15 \mu \mathrm{m}$, a characteristic of hHBs. This occurred within all KM-HAs (Fig. 3b-c). Only certain KM-HAs enriched viability (Fig. 3d), even though nuclear shape did not suggest cell death in other KM-HAs.

Functional assays of hepatic metabolism for KM-HA-embedded hepatic stem cell colonies-The hHpSCs embedded in different formulations of KM-HA hydrogels (Table 1) secreted AFP and albumin at increasing concentrations into medium throughout culture, whereas urea synthesis equilibrated by day 7 (Fig. 4). Distinctive estimates of these properties are calculated by normalizing to cell viability (Fig. 3d). AFP and albumin secretion rates always increased, and did so faster in KM-HAs with 1.2\% CMHA-S or less. 
In contrast, urea secretion rates only increased in KM-HAs with 1.2\% CMHA-S or less, and equilibrated or decreased in KM-HAs with 1.6\% CMHA-S (Fig. 4). Overall minimum secretion rates at day 7 corresponded to KM-HAs with 1.6\% CMHA-S and 0.4\% PEGDA (lettered formulation E, Fig. 2e), which also exhibited the highest viability (Fig. 4).

Gene expression in KM-HA-embedded hepatic stem cell colonies-The cells in KM-HA hydrogels transitioned to a phenotypic profile intermediate between that of hHpSCs and that of hHBs, as evidenced by increased expression of AFP and lowered levels of both E-cadherin (CDH1) and NCAM. The mRNA expression profiles in KM-HA-embedded hHpSCs were significantly different from those of hHpSCs on plastic and in KM but not from that of freshly isolated hHBs. For example, AFP was not expressed at all in freshly isolated $\mathrm{hHpSCs}$ or in those under self-replication conditions on plastic and in $\mathrm{KM}$, whereas hHpSCs embedded in KM-HA hydrogels contained cells expressing AFP but at levels much lower than found in freshly isolated or cultured hHBs. EpCAM mRNA expression in cells in KM-HA hydrogels was significantly higher than both hHpSCs and hHBs on culture plastic and in KM. Similarly, levels of mRNA expression of NCAM and CDH1 were significantly different from those of hHpSC colonies on plastic and in KM (Fig. 5 and Supplementary Fig. 1). CD44 expression varied across KM-HAs but within statistical boundaries of that of hHpSCs and hHBs, which overlapped (Fig. 5). In summary, the mRNA expression profiles of hHpSC colonies embedded in KM-HA hydrogels were intermediate between that in hHpSCs and hHBs.

Principal Component Analysis (PCA) of the mRNA expression profile data (Fig. 6) included assayed surface markers unique to hHpSCs (NCAM), those unique to hHBs (AFP) and those common to both hHpSCs and hHBs (CD44, EpCAM and CDH1). This analysis showed that two principal components (96\% cumulative variance) sufficiently described expression variation in the hHpSC-to-hHB differentiation phenomenon (Fig. 6a). Principal Component 1 (PC1) prescribed a longitudinal variation that was parallel to the differentiation trajectory in the PC plane, and accounted for $77 \%$ of the total variance. Principal Component 2 (PC2) prescribed the lateral variation orthogonal to differentiation, thus characteristic of intraphenotypic variation, and accounted for $19 \%$ of the total variance (Fig. 6a). On the one hand, marker contributions to PC1 revealed that EpCAM, NCAM, CDH1 and AFP equally described the differentiation process (PC1) of hHpSCs into hHBs on an individual basis under a quantitative scheme, as shown by the eigenvector of PC1. On the other hand, the PC2 eigenvector revealed that CD44 alone accounted for all of the intra-phenotypic variation $(\mathrm{PC} 2)$.

Data from hHpSC colonies in KM-HA hydrogels in the PC1-PC2 plane confirmed their genetic expression profile as an intermediate state between that of hHpSCs and hHBs, and revealed that the highest variations across KM-HAs were orthogonal to the differentiation direction (Fig. 6b and Supplementary Fig. 2). Data for embedded hHpSCs was significantly distinct from the hHB lineage stage, and also significantly distinct from the hHpSC lineage stage for KM-HA formulation C (Fig. 6c and d). When compared amongst each other, gene expression profiles for KM-HA-embedded hHpSCs distributed in the PC plane distinctively with respect to the CMHA-S content of each KM-HA formulation, most significantly in PC2. In other words, the amount of HA in KM-HAs contributed in dictating intraphenotypic variation for hHpSCs grown in different KM-HAs (Supplementary Fig. 3b and c).

Intra-phenotypic variation (PC2) for KM-HA-embedded hHpSCs has a nonlinear dependence on stiffness. The gene expression had increasing PC2 scores for KM-HA formulations with $\left|\mathrm{G}^{*}\right|<200 \mathrm{~Pa}$ and decreasing PC2 scores for stiffer KM-HA hydrogels (Figure 6d and Supplementary Fig. 3a). In the experiment, PC2 score peaked at KM-HA 
formulation $\mathrm{C}\left(\left|\mathrm{G}^{*}\right|=165 \mathrm{~Pa}\right)$. This trend was similar in the PC1 differentiation score (Figure 6c and Supplementary Fig. 3a).

In summary, this analysis showed that KM-HA-embedded hHpSCs acquired comparable intermediate phenotypes in their differentiation progression from $\mathrm{hHpSCs}$ to hHBs within certain KM-HA hydrogel formulations. When compared across KM-HA formulations, gene expression levels of KM-HA-hydrogel embedded hHpSCs were most distinct with respect to their intra-phenotypic variation, which was mainly dominated by CD44 expression and maximally expressed with hydrogel stiffness in the middle of the experimental range as in KM-HA formulation $\mathrm{C}\left(\left|\mathrm{G}^{*}\right|=165 \mathrm{~Pa}\right)$.

Protein expression in KM-HA-embedded hepatic stem cell colonies-AFP protein detection by immunostaining was scarce or null in KM-HA-grown hHpSCs, which agreed with low mRNA expression (Fig. 4). Due to this resolution constraint, ELISAs were used to compare AFP secretion with mRNA expression in KM-HA-embedded hHpSCs, showing qualitative correlation at day 7 for all KM-HAs (Fig. 7).

Fluorescence microscopy with thick sections (3-4 cell diameters) helped determine cumulative protein expression of EpCAM, NCAM, CD44 and CDH1 in KM-HA-embedded hHpSCs. All KM-HAs hydrogels contained EpCAM+, NCAM+ and CD44+ cells; however, CD44+ cells were enriched in KM-HA hydrogels with 1.2\% CMHA-S or less, whereas EpCAM+ and NCAM+ cells were evident in every formulation of KM-HA hydrogels. CDH1 protein expression paralleled mRNA expression in KM-HAs with $\left|\mathrm{G}^{*}\right|<200 \mathrm{~Pa}$, and was undetectable at higher stiffness levels (Fig. 7).

Confocal microscopy, which can elucidate whether changes in marker expression are general or exclusive to subpopulations of cells in the embedded hHpSC colonies, was performed both across KM-HA-hydrogel embedded hHpSC colonies and within their cells across optical planes less than a single cell diameter. Overall, there was little co-localization of EpCAM with all other surface markers (NCAM, CD44 and CDH1). Subsets of cells expressing all markers were at external colony surfaces in contact with KM-HA material. In addition, heterogeneous distribution of surface markers other than EpCAM in KM-HAembedded hHpSCs exhibited some degree of cell sorting with respect to their cell surface marker profile (Fig. 8). Within individual cells, EpCAM showed preference towards homotypic cell-cell interactions; NCAM and CDH1 appeared in contact with KM-HA hydrogel and without intracellular co-localization with EpCAM (Fig. 9).

\section{DISCUSSION}

To date, there is limited information about the effects of mechanical properties of a microenvironment on differentiation of cells from soft tissues like liver. Soft tissues are composed of maturational lineages of cells and gradients in the components, matrix and soluble signals, of the microenvironment. These gradients result in changes with respect to mechanical properties, depending partly on sulfation levels and patterns in the glycosaminoglycans (GAGs) amongst other matrix components [3]. The mechanical properties of the microenvironment regulate cellular functions via mechanotransduction during signaling, transport, and regenerative processes [26-28] and influence tissue assembly [29]. These types of mechanisms are increasingly understood in mesodermal derivatives: for example, substrate stiffness can induce differentiation in mesenchymal stem cells [30] and regulate formation of capillary-like structures from endothelial colonyforming cells on HA substrates [31]. In fact, progressing compliance of such HA substrates also influences maturation of chicken embryonic myocardial precursors [32]. 
Hyaluronic acid (HA) is a key component in the matrix chemistry of the hepatic stem cell niche. HA belongs to the glycosaminoglycan (GAG) family, and is formed by disaccharide units linked with alternating $\beta-1,4$ and $\beta-1,3$ glycosidic bonds between glucosamine and glucuronic acid structures. HA is found in matrix on cell surfaces and inside cells [33]. HA is conserved across all species, is biocompatible and elicits no inflammatory, immunologic or toxic responses [34]. Due to these properties along with high water saturation, HA is a great building block for biomaterials $[35,36]$. HA can be modified easily, and is more costeffective than other matrix molecules [25, 34, 37-39].

HA is a natural candidate for stem cell grafting, as it is abundant during embryogenesis, wound repair, and organ regeneration. Neural crest cell migration, cardiac development and prostate duct formation involve HA function as a scaffold component [40-43]. Rapidly dividing epithelial cells increase binding towards HA, and it is possible epithelialmesenchymal transitions occur through interactions mediated by HA binding [44, 45]. In hepatic tissues, HA interacts with liver progenitors through two HA receptors that mediate attachment to matrix: hHpSCs express CD44, and hABs express LYVE-1 [46-48]. In fact, in primary cultures and in liver injury, hepatic stellate cells produce HA, which increases in parallel with CD44 expression, and results in increased HA in the blood that correlates with hepatic regeneration in vivo [49].

Tissue engineering needs to replicate biochemical and mechanical properties of the cell environment $[50,51]$ but also needs to discriminate between biochemical and mechanical induction of differentiation, since cells require microenvironments with satisfactory mechanical properties for survival [52-56]. We have used HA hydrogels previously [25, 34, 37-39] and found empirical evidence that hHpSCs differentiated when seeded in mechanically stiff grafts $[12,57]$. In this work, we formally determined mechanical properties of KM-HA hydrogels and their effects on differentiation of hHpSCs by maintaining all other conditions (matrix components, diffusivity and culture media) equivalent.

Several KM-HA hydrogels, varying in levels of stiffness, had identical concentrations of either HAs or of their cross-linker, PEGDA (Table 1), allowing us to distinguish between biochemical and mechanical regulation of gene expression. These HA hydrogels, when mixed in buffered distilled water with different compositions, yield shear moduli ranging from 11 to $3500 \mathrm{~Pa}$ [25]. The results of KM-HA rheometry show that preparing these hydrogels in $\mathrm{KM}$ - in order to ensure seeded cells have nutrient access and optimal culture conditions during hydrogel mixing - changes the absolute values of their properties but still replicates expected rheological behavior qualitatively (e.g. stiffness linear in PEGDA concentration, no viscoelastic damping), confirming that the hydrogel chemistry is robust [25]. Added to their predictable stiffness (Fig. 2a), KM-HA hydrogels can transmit external forces to embedded cells without temporal damping, as the mechanical properties are dominated by the elastic component of the shear modulus $\left|\mathrm{G}^{*}\right|$ across a broad frequency range where the viscoelastic damping $\left|G^{\prime} / G^{\prime}\right| \approx 0$ (Fig. 1a). KM-HA hydrogels also exhibit a shear-thinning response to oscillatory shear forcing (Fig. 1b), which would allow delivering cell-seeded KM-HA hydrogels by extrusion in grafting applications for tissue engineering. KM-HAs also have, for signals $70 \mathrm{kDa}$ in size or less, diffusivities matching culture medium, thus providing a 3D environment with unhindered diffusion (Fig. 2b) [22].

The markers chosen to define gene expression in the stem cell niche populations are a subset of those identified for the three lineage stages of stem/progenitors: hHpSCs, hHBs and committed progenitors [58]. Many are expressed by all three stages including cytokeratins 8 and 18, Sonic and Indian hedgehog proteins, CXCR4, various transcription factors (e.g. SOX 9 and 17, HES1), and two chosen for these studies: epithelial cell adhesion molecule 
(EpCAM) and hyaluronan receptors (CD44). Yet, some uniquely identify one or another stage. The hHpSCs express neural cell adhesion molecule (NCAM) and high levels of CDH1, but do not express alpha-fetoprotein (AFP), ICAM-1 or any of the known P450s [14]. The hHBs strongly express AFP, P450A7, and ICAM-1 but not NCAM and express much lower levels of CDH1.

The conditions required for ex vivo maintenance of one lineage stage versus another are known. [20]. Self-replication of hHpSCs ex vivo requires KM [4, 18] and cells on culture plastic, on feeders of angioblasts, [14], on substratum of purified type III collagen [59], in uncross-linked HAs [4] or in mixtures of these. Lineage restriction to hHBs occurs in KM and on type IV collagen, laminin, highly cross-linked HA hydrogels or a mixture of these [4]. The cells in KM-HA hydrogels transitioned to cells ranging from these two and with most being intermediate in the phenotypic profile between hHpSCs and hHBs.

Distinct metabolic activities in KM-HA-hydrogel embedded cells (Fig. 4) depend on KMHA composition. Secretion rates of hepatic factors (AFP, albumin and urea) increased in KM-HA hydrogels with low HA but were paralleled by decreased cell viability. By contrast, secretion rates were lower in KM-HA hydrogels with higher levels of HA, conditions that resulted in higher viability and in increased growth of the cells (see results in the formulation E in Fig. 3d). Since hHpSCs and hHBs exhibit different phenotypic properties, the shift in the proportion of the cells with the hHpSC phenotype towards higher numbers with a hHB phenotype suggests that specific formulations of the KM-HA results either in differentiation of the hHpSCs to hHBs or selective expansion of hHBs.

Gene expression analyses of KM-HA-embedded hHpSCs colonies (Fig. 5) revealed distinctive patterns depending on which formulation of KM-HA hydrogel was used. EpCAM is a common marker of hHpSCs and hHBs and to less extent on the committed progenitors and is found characteristically in homotypic cell-cell interactions $[4,14,20]$. EpCAM mRNA expression in all KM-HA-embedded hHpSCS increased significantly above levels found in $\mathrm{hHpSC}$ or $\mathrm{hHB}$ colonies on plastic and in $\mathrm{KM}$. We attribute this to the acquisition of a 3D morphology when embedded within KM-HAs, necessitating additional homotypic interactions for colony cohesion.

CD44, another surface marker common to hHpSCs, hHBs and committed progenitors (Fig. 5 ), is enriched at the edges of the colonies at sites where there is heterotypic cell-cell interactions and is enriched in KM-HAs with low concentrations of HA (Fig. 7). We surmise that CD44 localization to cells in direct contact with HA reflects its function as a HA receptor. The heterogeneous distribution of CD44 within KM-HA-embedded hHpSC colonies (Figs. 8 and 9) elicits cell sorting for cells positive for CD44 as being adjacent to the HA. Therefore, these results could suggest that the heterogeneous distribution of cell surface markers in hHpSCs within KM-HAs may arise from differential adhesion amongst HA material and cells in hHpSC colonies. This phenomenon, historically known as the differential adhesion hypothesis [60], has been previously shown for other progenitor cells from developing tissues $[61,62]$.

NCAM, unlike EpCAM, is expressed by hHpSCs but not by hHBs or committed hepatocytic or biliary progenitors. Colonies of hHpSCs expressed NCAM at colony edges enabling heterotypic cell-cell interactions with angioblasts that also express it [4, 14, 20]. KM-HAembedded hHpSC colonies expressed NCAM (Fig. 7), distributed heterogeneously and preferentially on the outer boundaries of the colonies and on the apical surfaces of the external cells, sites for heterotypic cell-cell interactions (Figs. 8 and 9).

$\mathrm{CDH} 1$ is a marker for germline stem cells, induced pluripotent stem (iPS) cells [63-65] and is expressed by hHpSCs [20]. It is a cell surface protein that establishes homophilic 
adhesions between cells, induces mechanical responses through intracellular signaling cascades, and coordinates collective cell responses to mechanical forcing [66]. The effects of KM-HA hydrogel properties are drastic for $\mathrm{CDH} 1$ : protein expression depends on KMHA stiffness (Fig. 7). For KM-HA-embedded hHpSCs, there is a transition around $\left|\mathrm{G}^{*}\right|=$ $200 \mathrm{~Pa}$ for CDH1 protein expression, which is present in KM-HAs with $\left|\mathrm{G}^{*}\right|<200 \mathrm{~Pa}$ and null for $\left|\mathrm{G}^{*}\right|>200 \mathrm{~Pa}$. This trend is exclusive to $\mathrm{CDH} 1$ at the translational level, since CDH1 mRNA expression levels are comparable amongst KM-HAs across the experimental range of stiffness (Figs. 5 and 7). In other words, protein expression of CDH1 in KM-HAembedded hHpSC colonies exhibits a stiffness-dependent trend that is absent at the gene expression level. Hence, the mechanical properties of the microenvironment can also dictate changes in hHpSC phenotype. The distribution of $\mathrm{CDH} 1$ within KM-HA-embedded hHpSCs is also heterogeneous: it is expressed at apical surfaces of cells in outer surfaces of colonies exposed to HA (Figs. 8 and 9). We believe these exposed cells coordinate mechanical signals to adjacent cells, also exposed, through $\mathrm{CDH} 1$. By showing that translational control of CDH1 expression depends on environmental stiffness, we link signaling within hHpSCs with adaptation to the stiffness of the microenvironment. In summary, the data shows that some translational processes in hHpSCs obey a stiffness-dependent bifurcation, as confirmed by KM-HAs with equal concentrations of CMHA-S, PEGDA or comparable mRNA expression levels (Table 1, Figs. 3 and 4).

AFP is expressed uniquely by hHBs and to some extent by committed hepatocytic progenitors and, therefore, is a representative early hepatocytic lineage stage function $[9,14$, $58,67]$. It is a secreted protein involved as a serum carrier molecule for diverse factors (lipids, steroids, various proteins), and its functions are replaced in more mature liver cells by albumin having distinct binding properties to those of AFP [68]. We show that AFP mRNA expression levels vary across KM-HAs and that AFP mRNA and protein expressions correlate (Fig. 7).

Changes in gene expression for $\mathrm{hHpSC}$ colonies cultured in KM-HA hydrogels suggest modest influence towards differentiation occurring within these 3D environments. These gradual differentiation results in heterogenous cell populations ranging in phenotypes between that of the hHpSCs (intrahepatic lineage stage 1), hHBs (lineage stage 2) and, possibly, committed progenitors (lineage stage 3 ). This is indicated by the increase in the number of cells expressing AFP, loss of NCAM and, overall, in a multivariate scheme as shown by PCA (Fig. 6). The main source of gene expression variability across KM-HA formulations is orthogonal to the differentiation phenomenon. Most importantly, the resulting genetic expression profiles fall predominantly within an intermediate state between purified populations of hHpSCs and hHBs (Fig. 6b).

The PCA data shows that only one of the four differentiation markers tested (AFP, EpCAM, NCAM or CDH1) suffices to distinguish hHpSCs from hHBs, since their contribution to the multivariate expression profile variation is equal in magnitude. In addition, the sign of this contribution is concomitant with the direction that marker expression follows upon differentiation for all markers. This information is represented by the components of the PC1 eigenvector (Fig. 6a).

Gene expression assays of KM-HA embedded hHpSC colonies, both in an individual marker basis (Fig. 5) and through multivariate marker analysis (Fig. 6), can only evaluate the cumulative expression profile within the entire cell population in KM-HAs. In other words, the gene expression assays in this experiment do not discriminate against expression heterogeneity within $\mathrm{hHpSC}$ colonies because they average the expression profile across cells in populations that may be heterogeneous. In that respect, these gene expression results suggest that differentiation measurements intermediate between hHpSC colonies and hHB 
populations correspond to heterogeneous collections of hepatic progenitors. In other words, this interpretation suggests that $\mathrm{hHpSCs}$ within colonies grown in KM-HAs differentiate into hHBs individually. By reporting the relative amount of genetic expression for differentiation markers, the data also depicts a rate of conversion of an isolated population of $\mathrm{hHpSC}$ towards that of hHBs by single stochastic differentiation events. This interpretation is supported by heterogeneity in both cell morphology (Fig. 3) and protein expression in KM-HA-embedded hHpSC colonies (Figs. 8 and 9). Therefore, we conclude that differentiation is responsible for our genetic expression observations, that our measurements depict the pace at which it occurs within each KM-HA formulation, and that this pace depends on the properties of KM-HAs.

While it may be hoped that KM-HA moduli would correlate to a clear differentiation effect, or even single out an optimal modulus for differentiation, the situation is far more nuanced. For one, this experiment shows that KM-HA seeding with $\mathrm{hHpSC}$ colonies leads to heterogeneous constructs of hepatic progenitors. Additionally, this experiment shows that, for some markers, protein expression does not correlate with mRNA expression and depends on KM-HA stiffness, as happens with CDH1 (Fig. 7). In conjunction, these results suggest that KM-HA hydrogels induce hHpSCs to reconstitute the architecture of their stem cell niches, and that the effects of KM-HA hydrogel properties operate at both transcriptional and translational levels on $\mathrm{hHpSCs}$. Therefore, the acquired heterogeneity of $\mathrm{hHpSC}$ colonies seeded in KM-HA hydrogels might be preferred for tissue engineering since tissues require heterogeneous populations in vivo, both within stem cell niches that undergo regenerative processes and in mature tissues that perform specialized functions.

Fate determination comprises chromatin modifications such as methylation of chromatin followed by regulation of tissue-specific genes through classic signal-transduction pathways. Surveys of cells indicate that fate determination results qualitatively in the ability to express a given gene. Yet, the level of a given gene's expression - and its ability to be regulated by specific signals - occur as secondary events, often at later lineage stages of the cells. Only then, we can observe full expression and regulation of the gene in a given microenvironment. In other words, cell determination describes the degree to which cells acquire functions that their microenvironment requires, while complying with restrictions on gene expression imposed by their differentiated state. For example, the difference between genetic expression of AFP in hHpSCs and hHBs in these experiments is, on a firstimpression basis, insurmountable exclusively through KM-HA hydrogel seeding (Fig. 5). Even though the genetic expression assays for hHpSCs in KM-HA hydrogels suggest stochastic differentiation events within colonies, we cannot predict how effectively differentiated hHpSCs acquire functional characteristics of hHBs with this information alone, even though they might have a gene expression profile able to comply with hHB function.

The microenvironment dictates a cell's fate both qualitatively and quantitatively, and once fate is defined, also regulates its growth and tissue-specific gene expression at any given stage of the maturational process. Fate determination involves key chromatin modifications such as methylation processes, and only these can distinquish fate determination events from routine regulation; by contrast, changes in tissue-specific gene expression would occur both from fate determination events and/or regulation. Future differentiation studies with our KM-HA hydrogels could define factors involved in epigenetic phenomena and distinquishing these separable mechanisms. These alternative markers would allow rapid screening of hHpSC differentiation using only gene expression assays.

In practical terms, we have confirmed that the mechanical properties of a controllable microenvironment can be exploited to optimize 3D cultures of determined stem cell 
populations. For example, hHpSCs seeded in KM-HA formulation E hydrogels (CMHA-S $1.6 \%$, PEGDA $0.4 \%$ ) reside within a microenvironment with stiffness below the bifurcation of CDH1 expression, which supports increasing viability and, compared to other KM-HAs, yields the lowest levels of mature hepatic metabolism. In addition, the PCA scores reflect that, even though gene expression falls at an intermediate state between hHpSCs and hHBs, the location in the PC1-PC2 plane of the heterogeneous hHpSC colonies lies on the differentiation trajectory between both lineages and has an intraphenotypic variation with little excursion orthogonal to the differentiation path. Thus, we believe the best culture condition for $\mathrm{hHpSC}$ colonies sustainability in KM-HAs is formulation E. In the end, our experiments with KM-HA grown $\mathrm{hHpSCs}$ lead to one fundamental conclusion: that the mechanical properties of the microenvironment can also regulate differentiation processes in determined stem cell populations of endodermal origin.

\section{CONCLUSIONS}

In summary, we demonstrate that both the composition and mechanical properties of the microenvironment can regulate phenotypic changes and differentiation in human hepatic stem and descendent lineages of cells from parenchymal tissues such as liver. This study quantifies differentiation in a determined endodermal stem cell population embedded in a 3D microenvironment. Most notably, the experiment explores relations between differentiation, which occurrs in the absence of further biochemical supplementation in our model, and the controllable mechanical properties of the 3D microenvironment. Our work defines candidate ex vivo models for mechanotransduction research on stem cell populations. This model can study stem cell functions in 3D cultures, unlike other methods currently available, with straightforward control over their mechanical properties. Ultimately, our findings elucidate an approach to analyze the controls on expansion and differentiation in stem/progenitor cells from soft organs, such as liver, that incorporate both biochemical and mechanical properties in a separable fashion, which have an impact on parenchymal tissue engineering, cell-based therapies and development of bioreactors.

\section{Supplementary Material}

Refer to Web version on PubMed Central for supplementary material.

\section{Acknowledgments}

The Nucleic Acids Core Facility at UNC Chapel Hill provided oligonucleotide synthesis services for gene expression assays. The Histology Core Facility at UNC Chapel Hill provided cryosectioning services for the experiment. The Functional Genomics Core Facility at UNC Chapel Hill provided access to Real-Time PCR hardware. The Center for Gastrointestinal Biology and Diseases ImmunoTechnologies Core Facility at UNC Chapel Hill performed ELISA studies. All of the studies were financed by grants to LM Reid, including NIH grants (AA014243, IP30-DK065933), a Department of Energy Grant (DE-FG02-02ER-63477) and sponsored research grants from Vesta Therapeutics (Bethesda, MD) and GigaCyte (Branford, CT). Support for SR Lubkin provided in part by an NIH grant (R01GM096195). In addition, funding for one semester of OA Lozoya's salary and studies in R Superfine's lab were provided by an NIH project grant (5-P41-EB002025). Studies in F Guilak's lab were financed by an NIH grant (AR50245). Studies for development of the thiol-modified HA derivatives were financed by an NIH grant (DC04336) to GD Prestwich.

This article is dedicated posthumously to the memory of our research collaborator and friend, Dr. Claire Barbier who died in May, 2011, in recognition of her invaluable contributions to the performance of this work and preparation of this manuscript.

\section{Abbreviations}

With respect to specific cellular subpopulations, the species of origin is indicated by a small letter in front of the abbreviation ( $\mathrm{r}=\mathrm{rat} ; \mathrm{m}=$ mouse; $\mathrm{h}=$ human) 


\begin{tabular}{|c|c|}
\hline AFP & $\alpha$-fetoprotein \\
\hline ALB & albumin \\
\hline hABs & angioblasts, human \\
\hline CS-PG & chondroitin sulfate proteoglycan \\
\hline CD & common determinant \\
\hline CK & cytokeratin \\
\hline DS-PG & dermatan sulfate proteoglycan \\
\hline CDH1 & E-cadherin \\
\hline ЕрСАМ & epithelial cell adhesion molecule \\
\hline HS-PG & heparan sulfate proteoglycan \\
\hline HP-PG & heparin proteoglycan \\
\hline hHBs & hepatoblasts, human \\
\hline hHpSTCs & hepatic stellate cells, human \\
\hline hHpSCs & hepatic stem cells, human \\
\hline HA & hyaluronan \\
\hline CD44 & hyaluronan receptor \\
\hline ITGB1 & integrin sub-unit $\beta_{1}$ \\
\hline ITGB4 & integrin sub-unit $\beta_{4}$ \\
\hline ICAM & intercellular adhesion molecule \\
\hline NCAM & neural cell adhesion molecule \\
\hline PG & proteoglycan \\
\hline
\end{tabular}

\section{REFERENCES}

[1]. Gray, H.; Clemente, CD. Anatomy of the human body. 30th American ed.. Lea \& Febiger; Philadelphia: 1985.

[2]. Jungermann K, Katz N. Functional specialization of different hepatocyte populations. Physiol Rev. 1989; 69:708-64. [PubMed: 2664826]

[3]. Hayes AJ, Tudor D, Nowell MA, Caterson B, Hughes CE. Chondroitin sulfate sulfation motifs as putative biomarkers for isolation of articular cartilage progenitor cells. J Histochem Cytochem. 2008; 56:125-38. [PubMed: 17938280]

[4]. Wang Y, Yao H-L, Cui C-B, Wauthier E, Barbier C, Costello MJ, et al. Paracrine signals from mesenchymal cell populations govern the expansion and differentiation of human hepatic stem cells to adult liver fates. Hepatology. 2010; 52:1443-54. [PubMed: 20721882]

[5]. Martinez-Hernandez A, Amenta PS. The hepatic extracellular matrix. II. Ontogenesis, regeneration and cirrhosis. Virchows Arch A Pathol Anat Histopathol. 1993; 423:77-84. [PubMed: 8212543]

[6]. Martinez-Hernandez A, Amenta PS. The hepatic extracellular matrix. I. Components and distribution in normal liver. Virchows Arch A Pathol Anat Histopathol. 1993; 423:1-11. [PubMed: 8212529]

[7]. Martinez-Hernandez A, Amenta PS. The extracellular matrix in hepatic regeneration. FASEB J. 1995; 9:1401-10. [PubMed: 7589981] 
[8]. Martinez-Hernandez A, Delgado FM, Amenta PS. The extracellular matrix in hepatic regeneration. Localization of collagen types I, III, IV, laminin, and fibronectin. Lab Invest. 1991; 64:157-66. [PubMed: 1997730]

[9]. Turner R, Lozoya O, Wang Y, Cardinale V, Gaudio E, Alpini G, et al. Human hepatic stem cell and maturational liver lineage biology. Hepatology. 2011; 53:1035-45. [PubMed: 21374667]

[10]. Sigal SH, Rajvanshi P, Gorla GR, Sokhi RP, Saxena R, Gebhard DR Jr. et al. Partial hepatectomy-induced polyploidy attenuates hepatocyte replication and activates cell aging events. Am J Physiol. 1999; 276:G1260-72. [PubMed: 10330018]

[11]. Turner R, Gerber D, Reid L. The future of cell transplant therapies: a need for tissue grafting. Transplantation. 2010; 90:807-10. [PubMed: 20706179]

[12]. Turner WS, Schmelzer E, McClelland R, Wauthier E, Chen W, Reid LM. Human hepatoblast phenotype maintained by hyaluronan hydrogels. J Biomed Mater Res B Appl Biomater. 2007; 82:156-68. [PubMed: 17183559]

[13]. Lindros KO, Oinonen T, Issakainen J, Nagy P, Thorgeirsson SS. Zonal distribution of transcripts of four hepatic transcription factors in the mature rat liver. Cell Biol Toxicol. 1997; 13:257-62. [PubMed: 9298246]

[14]. Schmelzer E, Zhang L, Bruce A, Wauthier E, Ludlow J, Yao HL, et al. Human hepatic stem cells from fetal and postnatal donors. J Exp Med. 2007; 204:1973-87. [PubMed: 17664288]

[15]. Anatskaya OV, Vinogradov AE, Kudryavtsev BN. Hepatocyte polyploidy and metabolism/lifehistory traits: hypotheses testing. J Theor Biol. 1994; 168:191, 9. [PubMed: 8022197]

[16]. Duncan SA. Transcriptional regulation of liver development. Dev Dyn. 2000; 219:131-42. [PubMed: 11002334]

[17]. Reid LM, Jefferson DM. Culturing hepatocytes and other differentiated cells. Hepatology. 1984; 4:548-59. [PubMed: 6373552]

[18]. Kubota H, Reid LM. Clonogenic hepatoblasts, common precursors for hepatocytic and biliary lineages, are lacking classical major histocompatibility complex class I antigen. Proc Natl Acad Sci U S A. 2000; 97:12132-7. [PubMed: 11050242]

[19]. Kubota H, Yao HL, Reid LM. Identification and characterization of vitamin A-storing cells in fetal liver: implications for functional importance of hepatic stellate cells in liver development and hematopoiesis. Stem Cells. 2007; 25:2339-49. [PubMed: 17585172]

[20]. Wauthier E, Schmelzer E, Turner W, Zhang L, Lecluyse E, Ruiz J, et al. Hepatic stem cells and hepatoblasts: identification, isolation, and ex vivo maintenance. Methods Cell Biol. 2008; 86:137-225. [PubMed: 18442648]

[21]. Menard, KP. Dynamic mechanical analysis: a practical introduction. CRC Press; Boca Raton, FL: 2008.

[22]. Leddy HA, Guilak F. Site-specific molecular diffusion in articular cartilage measured using fluorescence recovery after photobleaching. Ann Biomed Eng. 2003; 31:753, 60. [PubMed: 12971608]

[23]. Pfaffl MW. A new mathematical model for relative quantification in real-time RT-PCR. Nucleic Acids Res. 2001; 29:e45. [PubMed: 11328886]

[24]. Schmittgen TD, Livak KJ. Analyzing real-time PCR data by the comparative C(T) method. Nat Protoc. 2008; 3:1101-8. [PubMed: 18546601]

[25]. Vanderhooft JL, Alcoutlabi M, Magda JJ, Prestwich GD. Rheological properties of cross-linked hyaluronan-gelatin hydrogels for tissue engineering. Macromol Biosci. 2009; 9:20-8. [PubMed: 18839402]

[26]. Chen Y, Dong XJ, Zhang GR, Shao JZ, Xiang LX. In vitro differentiation of mouse bone marrow stromal stem cells into hepatocytes induced by conditioned culture medium of hepatocytes. J Cell Biochem. 2007; 102:52-63. [PubMed: 17340623]

[27]. Purps O, Lahme B, Gressner AM, Meindl-Beinker NM, Dooley S. Loss of TGF-beta dependent growth control during HSC transdifferentiation. Biochem Biophys Res Commun. 2007; 353:8417. [PubMed: 17204247]

[28]. Kaimori A, Potter J, Kaimori JY, Wang C, Mezey E, Koteish A. Transforming growth factorbeta1 induces an epithelial-to-mesenchymal transition state in mouse hepatocytes in vitro. J Biol Chem. 2007; 282:22089-101. [PubMed: 17513865] 
[29]. Discher DE, Janmey P, Wang YL. Tissue cells feel and respond to the stiffness of their substrate. Science. 2005; 310:1139-43. [PubMed: 16293750]

[30]. Engler AJ, Sen S, Sweeney HL, Discher DE. Matrix elasticity directs stem cell lineage specification. Cell. 2006; 126:677-89. [PubMed: 16923388]

[31]. Yee D, Hanjaya-Putra D, Bose V, Luong E, Gerecht S. Hyaluronic Acid hydrogels support cordlike structures from endothelial colony-forming cells. Tissue Eng Part A. 2011; 17:1351-61. [PubMed: 21247340]

[32]. Young JL, Engler AJ. Hydrogels with time-dependent material properties enhance cardiomyocyte differentiation in vitro. Biomaterials. 2011; 32:1002-9. [PubMed: 21071078]

[33]. Tammi MI, Day AJ, Turley EA. Hyaluronan and homeostasis: a balancing act. J Biol Chem. 2002; 277:4581-4. [PubMed: 11717316]

[34]. Shu XZ, Liu Y, Luo Y, Roberts MC, Prestwich GD. Disulfide cross-linked hyaluronan hydrogels. Biomacromolecules. 2002; 3:1304-11. [PubMed: 12425669]

[35]. Burdick JA, Prestwich GD. Hyaluronic acid hydrogels for biomedical applications. Adv Mater. 2011; 23:H41-56. [PubMed: 21394792]

[36]. Prestwich GD. Hyaluronic acid-based clinical biomaterials derived for cell and molecule delivery in regenerative medicine. J Control Release. 2011 In Press.

[37]. Shu XZ, Ahmad S, Liu Y, Prestwich GD. Synthesis and evaluation of injectable, in situ crosslinkable synthetic extracellular matrices for tissue engineering. J Biomed Mater Res A. 2006; 79:902-12. [PubMed: 16941590]

[38]. Shu XZ, Liu Y, Palumbo F, Luo Y, Prestwich GD. In situ crosslinkable hyaluronan hydrogels for tissue engineering. Biomaterials. 2004; 25:1339-48. [PubMed: 14643608]

[39]. Shu, XZ.; Prestwich, GD. Therapeutic biomaterials from chemically modified hyaluronan. In: Garg, H.; Hales, C., editors. Chemistry and Biology of Hyaluronan. Elsevier Press; Amsterdam: 2004. p. 475-504.

[40]. Luo Y, Kirker KR, Prestwich GD. Cross-linked hyaluronic acid hydrogel films: new biomaterials for drug delivery. J Control Release. 2000; 69:169-84. [PubMed: 11018555]

[41]. Pouyani T, Prestwich GD. Functionalized derivatives of hyaluronic acid oligosaccharides: drug carriers and novel biomaterials. Bioconjug Chem. 1994; 5:339-47. [PubMed: 7948100]

[42]. Shepard S, Becker H, Hartmann JX. Using hyaluronic acid to create a fetal-like environment in vitro. Ann Plast Surg. 1996; 36:65, 9. [PubMed: 8722987]

[43]. Vrochides D, Papanikolaou V, Pertoft H, Antoniades AA, Heldin P. Biosynthesis and degradation of hyaluronan by nonparenchymal liver cells during liver regeneration. Hepatology. 1996; 23:1650-5. [PubMed: 8675189]

[44]. Toole BP, Wight TN, Tammi MI. Hyaluronan-cell interactions in cancer and vascular disease. J Biol Chem. 2002; 277:4593-6. [PubMed: 11717318]

[45]. Brown TJ, Laurent UB, Fraser JR. Turnover of hyaluronan in synovial joints: elimination of labelled hyaluronan from the knee joint of the rabbit. Exp Physiol. 1991; 76:125-34. [PubMed: 2015069]

[46]. Hu M, Sabelman EE, Lai S, Timek EK, Zhang F, Hentz VR, et al. Polypeptide resurfacing method improves fibroblast's adhesion to hyaluronan strands. J Biomed Mater Res. 1999; 47:79_ 84. [PubMed: 10400884]

[47]. Aruffo A, Stamenkovic I, Melnick M, Underhill CB, Seed B. CD44 is the principal cell surface receptor for hyaluronate. Cell. 1990; 61:1303-13. [PubMed: 1694723]

[48]. Wilting J, Buttler K, Schulte I, Papoutsi M, Schweigerer L, Manner J. The proepicardium delivers hemangioblasts but not lymphangioblasts to the developing heart. Dev Biol. 2007; 305:451-9. [PubMed: 17383624]

[49]. Ogata T, Okuda K, Ueno T, Saito N, Aoyagi S. Serum hyaluronan as a predictor of hepatic regeneration after hepatectomy in humans. Eur J Clin Invest. 1999; 29:780-5. [PubMed: 10469166]

[50]. Prestwich GD. Engineering a clinically-useful matrix for cell therapy. Organogenesis. 2008; 4:42-7. [PubMed: 19279714] 
[51]. Prestwich, GD.; Ghaly, T.; Brudnicki, P.; Ratliff, B.; Goligorsky, MS. Bioartificial Stem Cell Niches: Engineering a Regenerative Microenvironment. In: Goligorsky, MS., editor. Regenerative Nephrology. Academic Press; San Diego: 2011. p. 245-56.

[52]. Loboa EG, Wren TA, Beaupre GS, Carter DR. Mechanobiology of soft skeletal tissue differentiation--a computational approach of a fiber-reinforced poroelastic model based on homogeneous and isotropic simplifications. Biomech Model Mechanobiol. 2003; 2:83-96. [PubMed: 14586808]

[53]. Forgacs, G.; Newman, SA. Biological Physics of the Developing Embryo. Cambridge University Press; 2005.

[54]. Lubkin SR, Murray JD. A mechanism for early branching in lung morphogenesis. J Math Biol. 1995; 34:77-94. [PubMed: 8568422]

[55]. Forgacs G, Foty RA, Shafrir Y, Steinberg MS. Viscoelastic properties of living embryonic tissues: a quantitative study. Biophys J. 1998; 74:2227-34. [PubMed: 9591650]

[56]. Foty RA, Forgacs G, Pfleger CM, Steinberg MS. Liquid properties of embryonic tissues: Measurement of interfacial tensions. Phys Rev Lett. 1994; 72:2298-301. [PubMed: 10055839]

[57]. Turner WS, Seagle C, Galanko JA, Favorov O, Prestwich GD, Macdonald JM, et al. Nuclear magnetic resonance metabolomic footprinting of human hepatic stem cells and hepatoblasts cultured in hyaluronan-matrix hydrogels. Stem Cells. 2008; 26:1547-55. [PubMed: 18323408]

[58]. Schmelzer E, Wauthier E, Reid LM. The phenotypes of pluripotent human hepatic progenitors. Stem Cells. 2006; 24:1852-8. [PubMed: 16627685]

[59]. McClelland R, Wauthier E, Zhang L, Melhem A, Schmelzer E, Barbier C, et al. Ex vivo conditions for self-replication of human hepatic stem cells. Tissue Eng Part C Methods. 2008; 14:341-51. [PubMed: 18844603]

[60]. Steinberg MS. Reconstruction of tissues by dissociated cells. Some morphogenetic tissue movements and the sorting out of embryonic cells may have a common explanation. Science. 1963; 141:401-8. [PubMed: 13983728]

[61]. Foty RA, Steinberg MS. The differential adhesion hypothesis: a direct evaluation. Dev Biol. 2005; 278:255-63. [PubMed: 15649477]

[62]. Krieg M, Arboleda-Estudillo Y, Puech PH, Kafer J, Graner F, Muller DJ, et al. Tensile forces govern germ-layer organization in zebrafish. Nat Cell Biol. 2008; 10:429-36. [PubMed: 18364700]

[63]. Chen HF, Chuang CY, Lee WC, Huang HP, Wu HC, Ho HN, et al. Surface Marker Epithelial Cell Adhesion Molecule and E-cadherin Facilitate the Identification and Selection of Induced Pluripotent Stem Cells. Stem Cell Rev. 2011 In Press.

[64]. Chen T, Yuan D, Wei B, Jiang J, Kang J, Ling K, et al. E-cadherin-mediated cell-cell contact is critical for induced pluripotent stem cell generation. Stem Cells. 2010; 28:1315-25. [PubMed: 20521328]

[65]. Inaba M, Yuan H, Salzmann V, Fuller MT, Yamashita YM. E-cadherin is required for centrosome and spindle orientation in Drosophila male germline stem cells. PLoS One. 2010; 5:e12473. [PubMed: 20824213]

[66]. Smutny M, Yap AS. Neighborly relations: cadherins and mechanotransduction. J Cell Biol. 2010; 189:1075-7. [PubMed: 20584914]

[67]. Schmelzer, E.; McClelland, R.; Melhem, A.; Zhang, L.; Yao, H.; Wauthier, E., et al. Hepatic Stem Cells and the Liver's Maturational Stages: Implications for Liver Biology, Gene Expression, and Cell Therapies. In: Potten, C.; Clarke, R.; Wilson, J.; Renehan, A., editors. Tissue Stem Cells. Taylor \& Francis, Inc.; New York: 2006. p. 161-214.

[68]. Kubota H, Storms RW, Reid LM. Variant forms of alpha-fetoprotein transcripts expressed in human hematopoietic progenitors. Implications for their developmental potential towards endoderm. J Biol Chem. 2002; 277:27629-35. [PubMed: 12006569] 


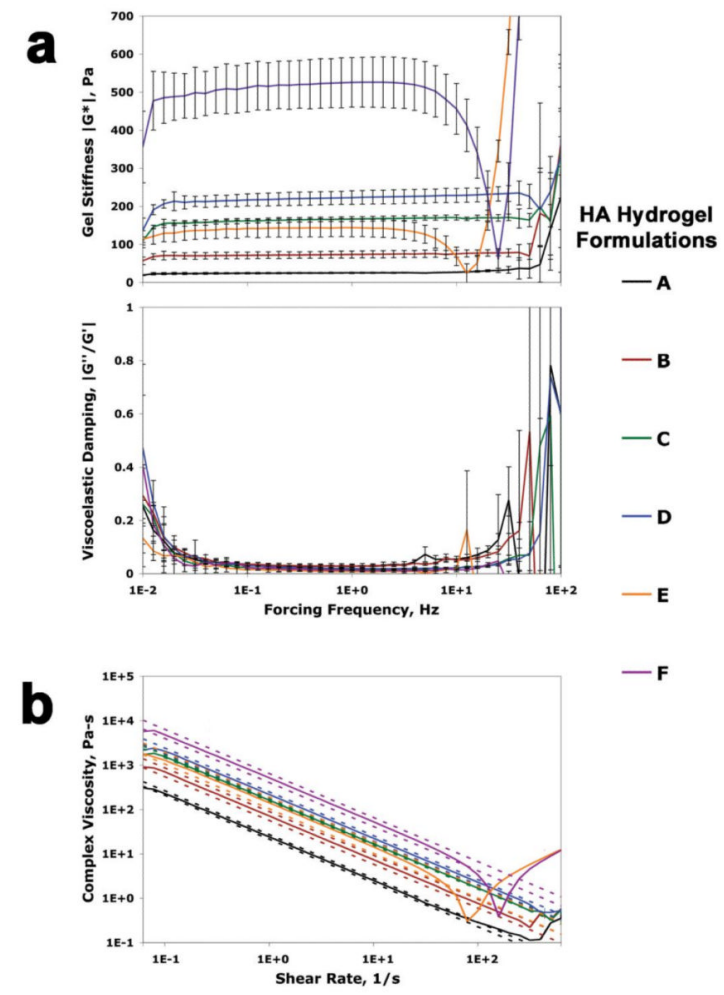

Figure 1.

Rheological measurements on KM-HAs. a) The shear modulus $\left|G^{*}\right|$ of KM-HAs, a measurement of mechanical gel stiffness, remains constant, whereas viscoelastic damping | G'/G'|, a measurement of deformation response delay upon external forcing, is negligible within the $0.1 \mathrm{~Hz}-10 \mathrm{~Hz}$ forcing frequency range for each of the formulations tested. Error bars: $95 \%$ confidence interval of measurements at each frequency tested. b) KM-HAs exhibit shear thinning, i.e. decrease in viscosity with increasing forcing frequencies, across experimental $0.61 / \mathrm{s}-60 \mathrm{1} / \mathrm{s}$ shear rate range $[0.1 \mathrm{~Hz}-10 \mathrm{~Hz}$ forcing frequency]; upper and lower limits: power law model-based 95\% confidence interval (Cox-Merz rule assumption, $\mathrm{R} 2>0.993$ for all formulations in the $0.31 / \mathrm{s}-301 / \mathrm{s}$ shear rate range $[0.05 \mathrm{~Hz}-5 \mathrm{~Hz}$ forcing frequency]). Rheological measurements performed only on lettered formulations shown in Table 1. 

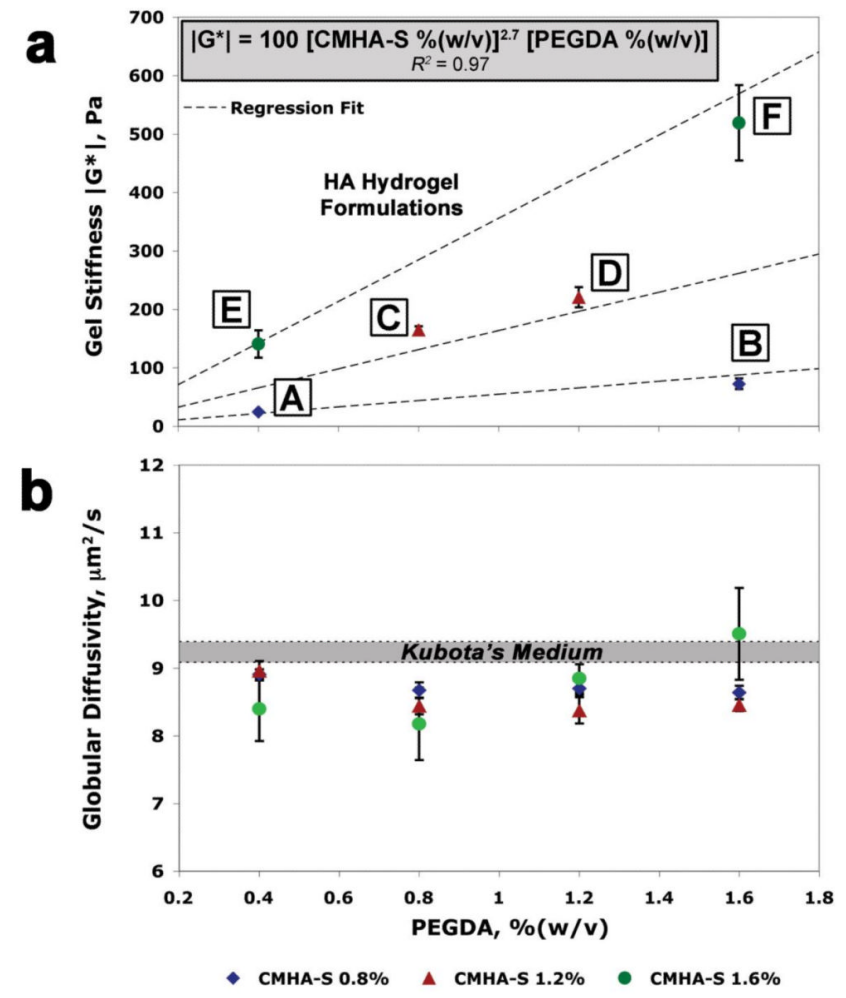

Figure 2.

Mechanical characterization of KM-HAs. a) Stiffness of KM-HAs is controllable and depends on CMHA-S and PEGDA contents. The average shear modulus $\left|G^{*}\right|$ increases with increasing CMHA-S and PEGDA contents following a power-law behavior, thus providing direct control of the final mechanical properties of KM-HAs during the initial hydrogel mixing; rheological measurements performed only on lettered formulations shown in Table 1. Error bars: \pm 1 standard deviation for measurements in the $0.05 \mathrm{~Hz}-5 \mathrm{~Hz}$ forcing frequency. b) Diffusion in KM-HAs. Measurements of diffusivity within KM-HAs by FRAP (70 kDa fluorescein-labeled dextran) do not differ significantly from Kubota's medium alone; diffusivity measurements performed on all formulations shown in Table 1. Error bars: $95 \%$ confidence interval of measurements. 


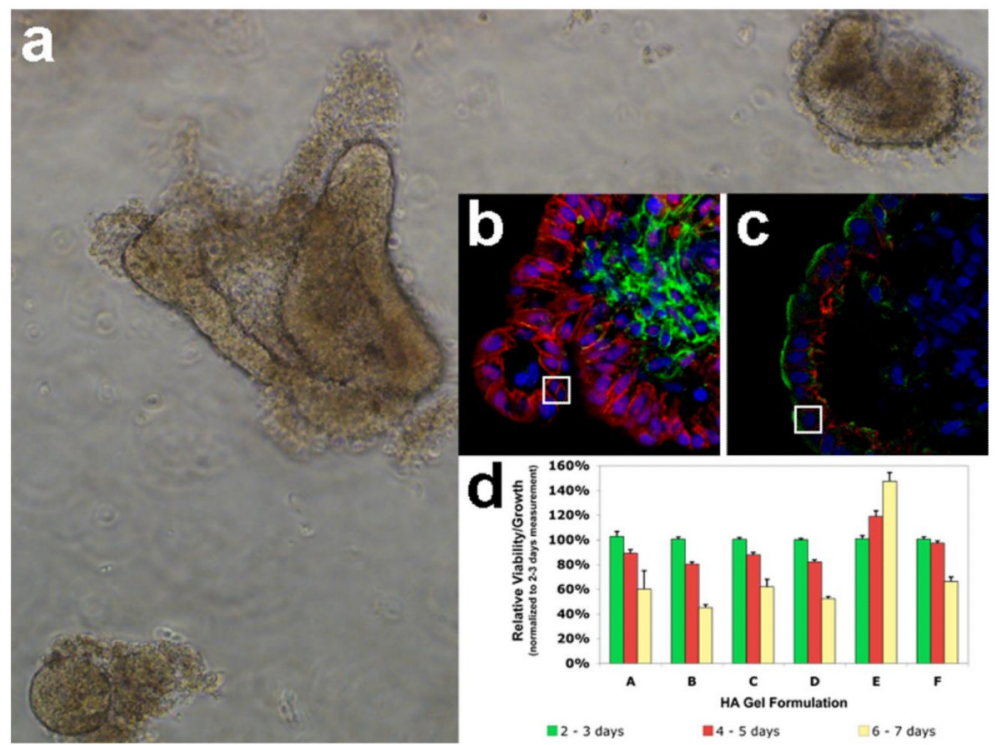

Figure 3.

Size, morphology and proliferation of hHpSCs in KM-HAs. Colonies of hHpSCs acquire three-dimensional configurations and exhibit a) spheroid-like agglomeration (bottom left) or folding (middle, top right) upon seeding in KM-HAs [image frame: $900 \mu \mathrm{m} \times 1200 \mu \mathrm{m}$ ].

Confocal microscopy on histological sections of hHpSC-seeded KM-HAs reveals mixed cell morphology phenotypes after 1 week of culture, with cell sizes of b) about $7 \mu \mathrm{m}$, or c) up to 10-15 $\mu \mathrm{m}$ amongst parenchymal cells [cell nuclei in blue from DAPI counterstaining, EpCAM in red for both b) and c), green for either b) CD44, or c) CDH1; image frames b) and c): $150 \mu \mathrm{m} \times 150 \mu \mathrm{m}$; white highlight in b) and c): $15 \mu \mathrm{m} \times 15 \mu \mathrm{m}]$. d) Viability of hHpSCs in KM-HAs, measured by alamarBlue metabolic reduction, reveals functional recovery and proliferation in KM-HA hydrogels with $1.6 \%(\mathrm{w} / \mathrm{v}) \mathrm{CMHA}-\mathrm{S}$ and $0.4 \%(\mathrm{w} / \mathrm{v})$ PEGDA (formulation E, Table 1) throughout 1 week of culture; alamarBlue reduction measurements after 24-hr incubation, normalized with respect to measurements at 2-3 days post-seeding; data reported as mean \pm standard error. 

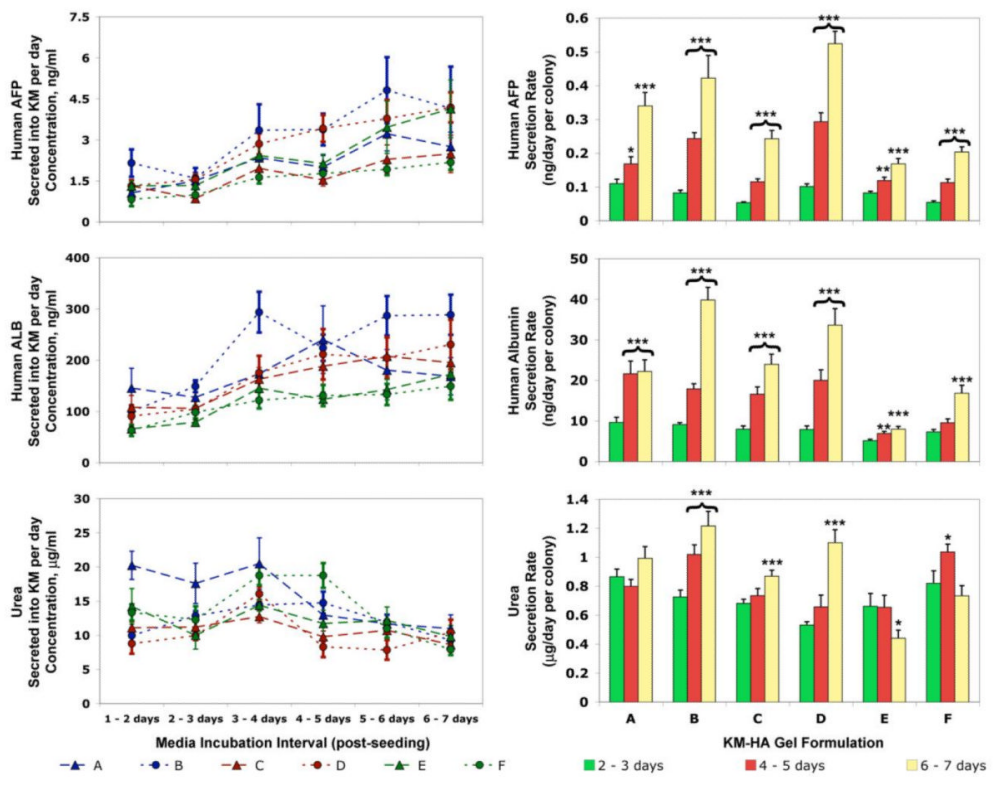

Figure 4.

Secretion of human AFP, albumin and urea by hHpSCs seeded into KM-HAs. Colonies of hHpSCs in KM-HAs exhibit some hepatic function with increasing concentrations of human AFP and albumin found in culture media (KM) and equilibration of urea synthesis by day 7 post-seeding. The metabolic secretion rates of human AFP, human albumin and urea are distinctive by day 7 post-seeding amongst KM-HA formulations, with minimum rates for AFP, albumin and decreased urea synthesis in KM-HAs with 1.6\% (w/v) CMHA-S and $0.4 \%$ (w/v) PEGDA (formulation E, Table 1). Left column: metabolite concentration in culture media collected daily after 24-hr incubation for each lettered formulation (Table 1). Right column: metabolite mass secretion rate per hHpSC colony in culture media after 24-hr incubation; total metabolite mass in media is normalized to number of functional hHpSC colonies at each interval as calculated by viability assay with alamarBlue reduction (Figure 3d; approximate number of colonies seeded per sample: 12). Significance levels for secretion rates of hepatic factors per hHpSC colony (p-value: $*<0.05, * *<0.01, * * *<$ 0.001 ) are reported with respect to secretion rates at the $2-3$ day interval for each KM-HA formulation (two-tailed Student's t-test). All data reported as mean \pm standard error. 

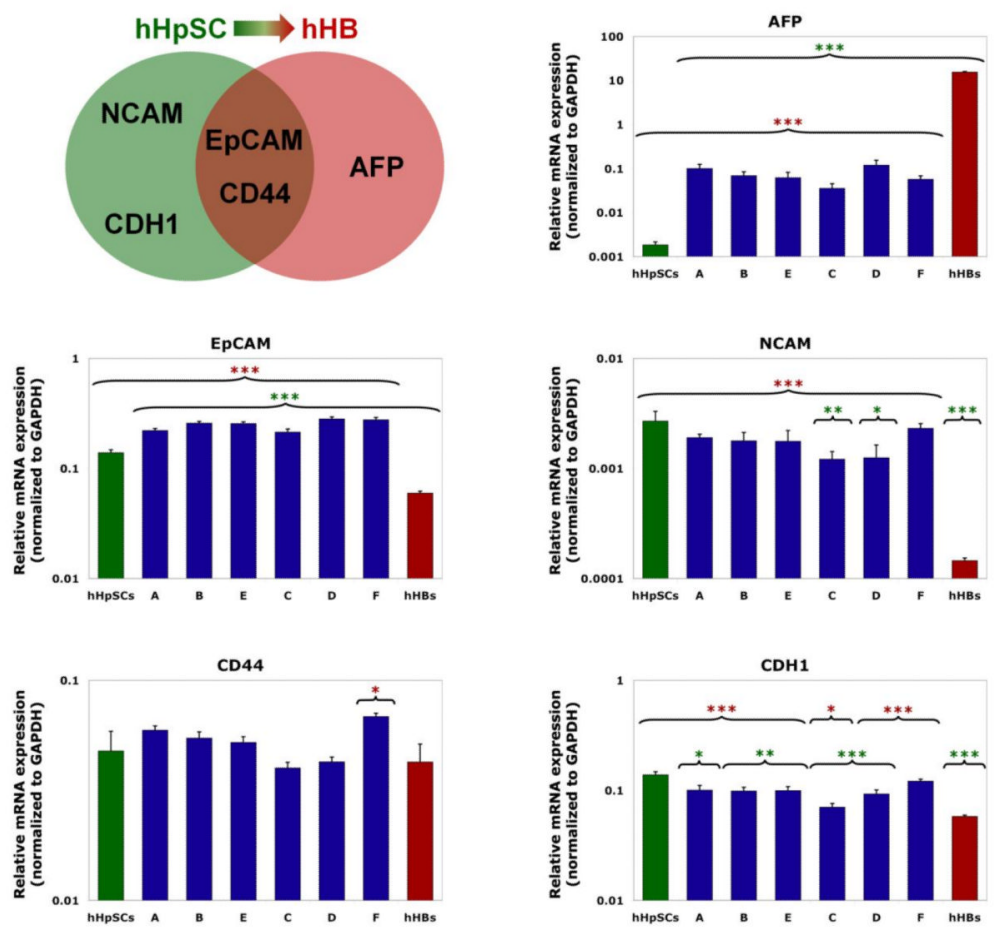

Figure 5.

Gene expression levels by qRT-PCR for hepatic progenitor markers in KM-HA-embedded hHpSCs after 1 week of culture (previous page). Comparisons between the mRNA expression levels of markers for hHpSCs and their immediate descendents hHBs (hepaticspecific AFP, EpCAM, NCAM, CD44 and CDH1) show that KM-HA-embedded hHpSCs acquire early $\mathrm{hHB}$ characteristics at the transcriptional level in passive culture for 1 week. The expression ranges in $\mathrm{hHpSC}$ and freshly isolated hHBs for CD44 are comparable; the expression levels for the remaining markers are statistically distinct, with approximately 2fold decrease in EpCAM, 3-fold decrease in CDH1, NCAM silencing and AFP enrichment upon hHpSCs differentiation into hHBs. In all KM-HAs, mean expression levels of seeded hHpSCs for AFP, NCAM and CDH1 shifted outside the hHpSC range towards the hHB range, while EpCAM expression is enriched throughout, after 1 week of culture. KM-HA formulations ordered by stiffness $\left|\mathrm{G}^{*}\right|(\mathrm{Pa})$ : A (25), B (73), E (140), C (165), D (220), F (520). Expression levels (mean \pm standard error) were normalized with respect to GAPDH. Measurements in lettered KM-HA formulations (Table 1) compared to hHpSC colonies (green) and freshly isolated hHBs (red) for significance (two-tailed Student's t-test). 

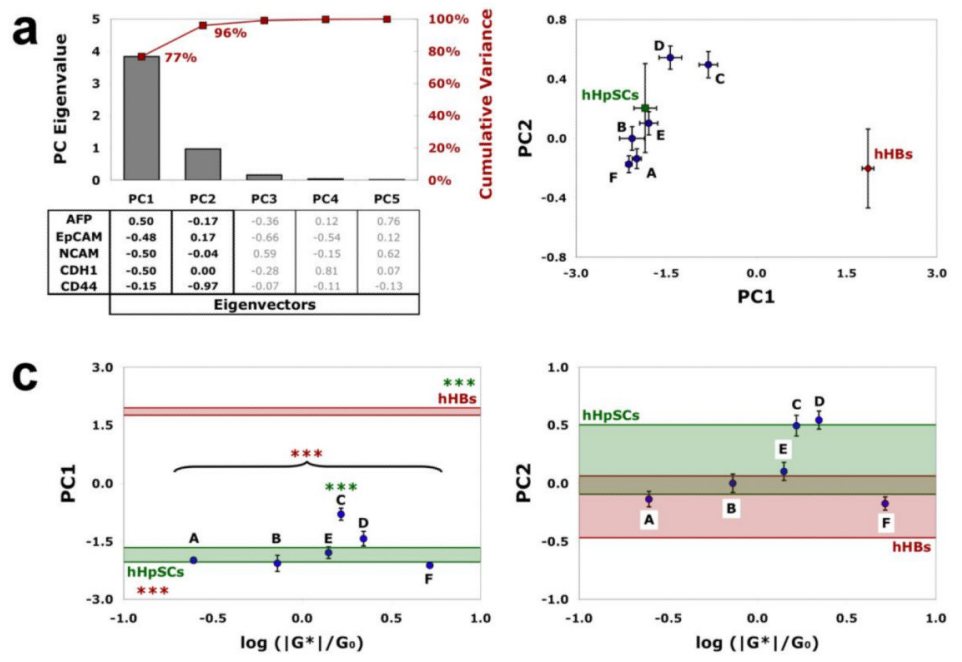

Figure 6.

Principal Component Analysis (PCA) of gene expression profile. a) Two principal components (PCs) account for 96\% of variance in gene expression profile between hHpSCs and hHBs with respect to hepatic progenitor markers (hepatic-specific AFP, EpCAM, NCAM, CD44 and CDH1); principal component 1 (PC1) describes differentiation and depends mostly on differences between hHpSCs and hHBs lineages with respect to differentiation markers (AFP, EpCAM, NCAM and CDH1) as shown by PC1 eigenvector; PC2 describes intra-phenotype variation and depends almost exclusively on CD44 expression. b) KM-HA-embedded hHpSCs show an intermediate phenotype between hHpSCs and hHBs in PC space. Gene expression profiles in KM-HA-embedded hHpSCs exhibit differences from $\mathrm{hHpSCs}$ and $\mathrm{hHBs}$ c) in PC1, and d) in PC2. The expression in KM-HA-embedded hHpSCs, as shown in c) and d), exhibits a trend with respect to KM-HA stiffness. Measurements in lettered KM-HA formulations (Table 1) compared to hHpSC colonies (green) and freshly isolated hHBs (red) for significance (two-tailed Student's ttest). Expression profile scores in PC space (error bars: mean \pm standard error) for lettered KM-HA formulations (Table 1) are plotted in c) and d) against normalized KM-HA shear modulus $\mid \mathrm{G}^{*} / \mathrm{G}_{0}\left(\mathrm{G}_{0}=100 \mathrm{~Pa}\right)$ and compared to threshold ranges of expression in $\mathrm{hHpSCs}$ (green area, mean \pm standard error) and freshly isolated hHBs (red area, mean \pm standard error). 


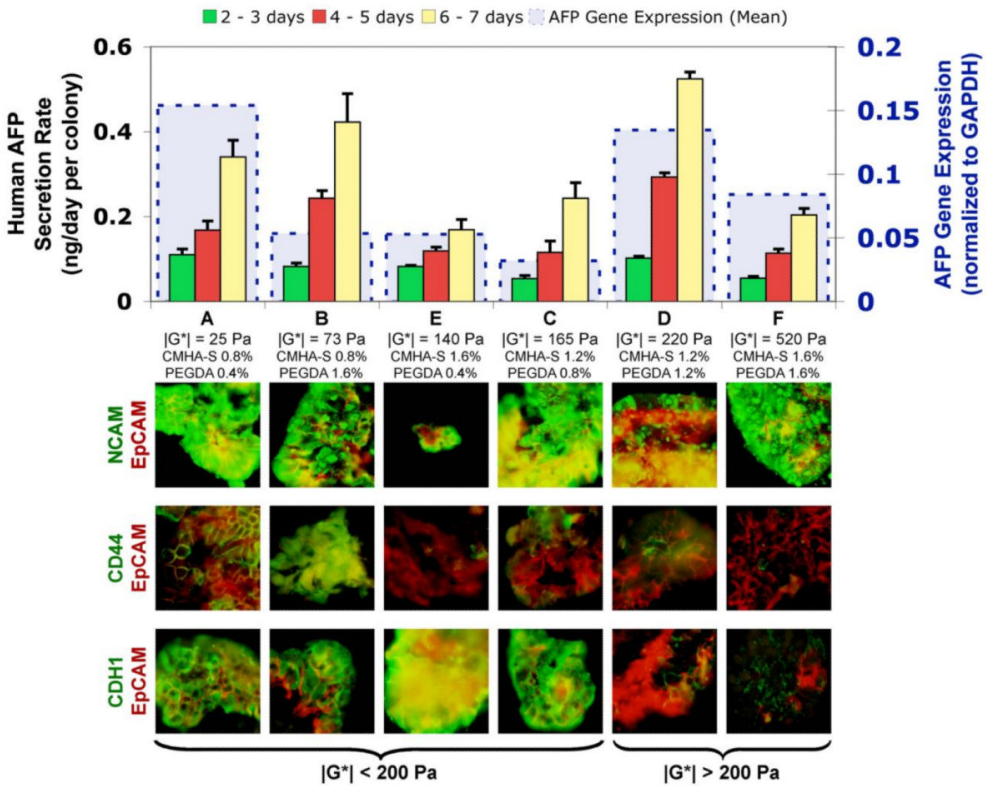

Figure 7.

Protein expression of differentiation markers in KM-HA-seeded hHpSCs after 1 week of culture. Colonies of hHpSCs exhibit differential levels of expression for differentiation markers in hHpSCs at the translational level depending on KM-HAs properties. Metabolic secretion rates of human AFP correlate mRNA expression levels across KM-HA formulations. All KM-HAs exhibit NCAM expression, while CD44 expression is richest in KM-HAs with CMHA-S contents of $1.2 \%$ (w/v) or less (lettered formulations A, B, C, D; Table 1). KM-HA hydrogels with $\left|\mathrm{G}^{*}\right|<200 \mathrm{~Pa}$ express $\mathrm{CDH} 1$, whereas $\mathrm{CDH} 1$ protein expression is null for KM-HA hydrogels with $\left|\mathrm{G}^{*}\right|>200 \mathrm{~Pa}$. Data for human AFP secretion rate reported as mean \pm standard error. Immunohistochemical staining for EpCAM, NCAM, CD44 and CDH1 performed on $15-20 \mu \mathrm{m}$ sections ( 2 to $3 \mathrm{hHpSCs}$ thick; hHpSC diameter: 5-7 $\mu \mathrm{m}$ ) and imaged by fluorescence microscopy [image frames: $100 \mu \mathrm{m} \times 100$ $\mu \mathrm{m}]$. KM-HA formulations ordered by stiffness $\left|\mathrm{G}^{*}\right|(\mathrm{Pa})$ : A (25), B (73), E (140), C (165), $\mathrm{D}(220), \mathrm{F}(520)$. 


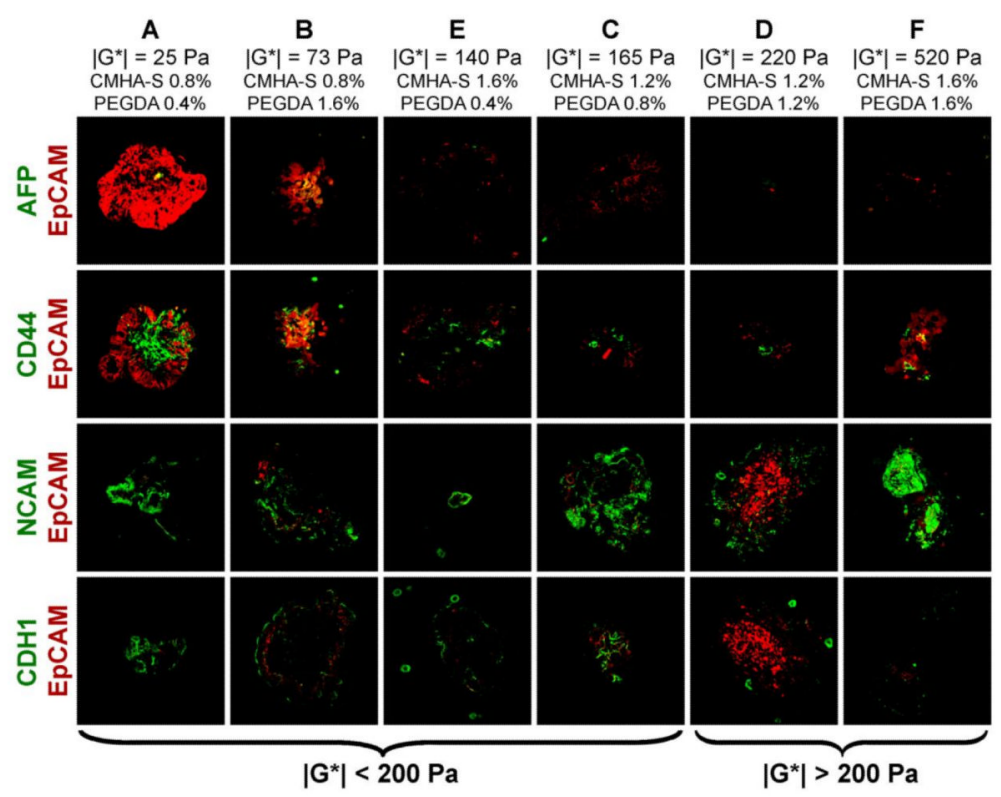

Figure 8.

Co-localization of differentiation markers in KM-HA-seeded hHpSC colonies. Colonies of hHpSCs exhibit low expression levels of AFP by immunohistochemistry. Co-localization of EpCAM with other cell surface differentiation markers (NCAM, CD44, CDH1) is low or null across cells within KM-HA-seeded hHpSC colonies. Staining for AFP, EpCAM, NCAM, CD44 and CDH1 performed on $15-20 \mu \mathrm{m}$ sections and imaged by laser confocal microscopy. Images depict average fluorescence collected across 11 confocal optical sections of $0.407 \mu \mathrm{m}$ [mean filtering, total optical slice: $4.07 \mu \mathrm{m}$; image frames: $300 \mu \mathrm{m} \times$ $300 \mu \mathrm{m}]$. KM-HA formulations sorted and displayed with respect to increasing shear modulus $\left|\mathrm{G}^{*}\right|$. 

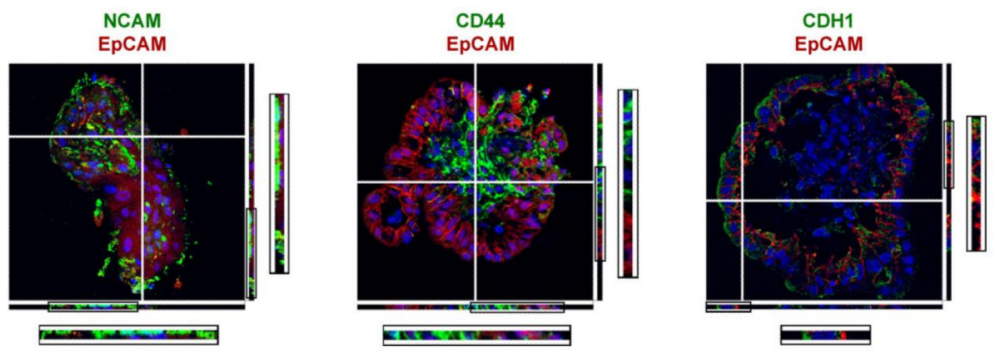

Figure 9.

Cellular distribution of cell surface differentiation markers in hHpSCs seeded in KM-HA hydrogels. EpCAM is expressed in individual cells at "inner" surfaces of hHpSC colonies with homotypic cell-cell interactions. NCAM (left frame, KM-HA formulation F from Figure 8) and CDH1 (right frame, KM-HA formulation B from Figure 8) are expressed only in cells at "outer" surfaces of hHpSC colonies, in direct contact with KM-HA hydrogels, and exposed to heterotypic cell-cell interactions. CD44 (middle frame, KM-HA formulation A from Figure 8) is expressed in a subset of cells having the smallest cell sizes, poor colocalization with EpCAM expression, and in contact with KM-HAs (folded colony). Sagittal projections of full optical sections (Z-stack total optical slice: $4.07 \mu \mathrm{m}$ ) show enriched EpCAM expression on the basal surfaces of individual cells; NCAM and CDH1 expression is exclusive to apical surfaces of individual cells. Staining for EpCAM, NCAM, CD44 and CDH1 performed on $15-20 \mu \mathrm{m}$ sections and imaged by laser confocal microscopy. Images depict sagital projections ( $\mathrm{X}$ and $\mathrm{Y}$, through white crosshairs) of collected fluorescence across a Z-stack of 11 confocal optical sections of $0.407 \mu \mathrm{m}$ [cell nuclei in blue from DAPI counterstaining; Z-view frames: $225 \mu \mathrm{m} \times 225 \mu \mathrm{m}$, confocal section 6 of 11]. 


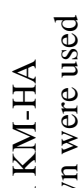

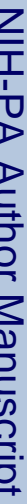

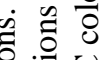

营设

它

可要

$\sum_{\mathbb{D}}$

政灵

峞遥

再

.

ง $\approx$ 。

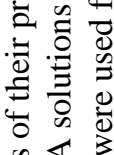

苗藏

- एण

은

娄范

II

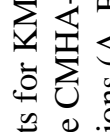

$\stackrel{0}{=}$

离

중.

官完

刍过

눰

\%

党

ส 듀

啳

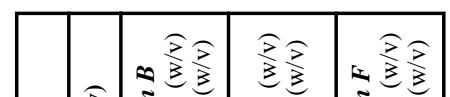

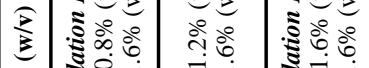

官

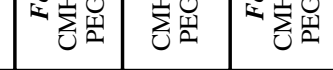

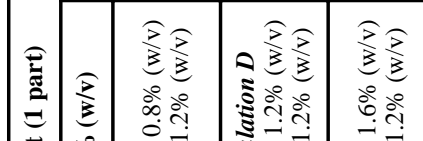

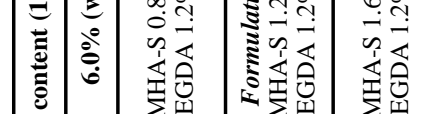

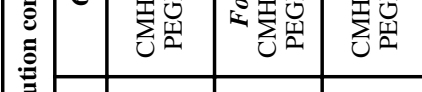

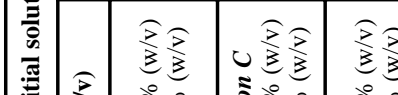

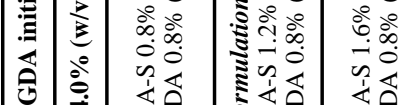

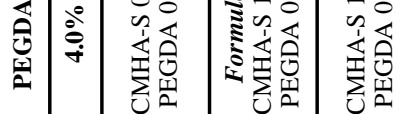

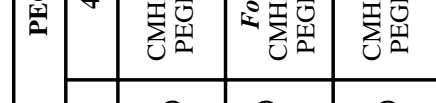

\begin{tabular}{|c|c|c|c|}
\hline 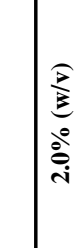 & 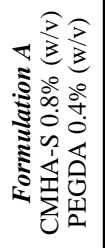 & 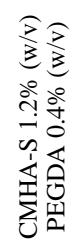 & 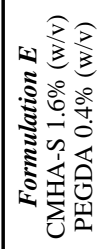 \\
\hline \multirow{2}{*}{ 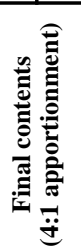 } & 弲尽 & 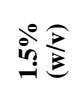 & $\stackrel{8}{3}$ \\
\hline & \multicolumn{3}{|c|}{ 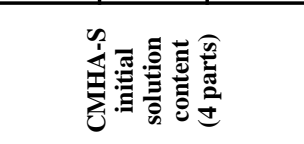 } \\
\hline
\end{tabular}

Biomaterials. Author manuscript; available in PMC 2012 October 1. 